\title{
Where People Live and Die Makes a Difference: Individual and Geographic Disparities in Well-Being Progression at the End of Life
}

\author{
Denis Gerstorf and Nilam Ram \\ Pennsylvania State University, Max Planck Institute \\ for Human Development, and DIW Berlin \\ Jürgen Schupp \\ DIW Berlin and Free University of Berlin
}

\author{
Jan Goebel \\ DIW Berlin
}

\author{
Ulman Lindenberger \\ Max Planck Institute for Human Development
}

\author{
Gert G. Wagner \\ Max Planck Institute for Human Development, DIW Berlin, and Berlin University of Technology
}

\begin{abstract}
Life-span psychological research has long been interested in the contextual embeddedness of individual development. To examine whether and how regional variables relate to between-person disparities in the progression of late-life well-being, we applied three-level growth curve models to 24-year longitudinal data from deceased participants of the German Socio-Economic Panel Study $(N=3,427$; age at death $=$ 18 to 101 years). Results indicated steep declines in well-being with impending death, with some $8 \%$ of the between-person differences in both level and decline of well-being reflecting between-county differences. Exploratory analyses revealed that individuals living and dying in less affluent counties reported lower late-life well-being, controlling for key individual predictors, including age at death, gender, education, and household income. The regional variables examined did not directly relate to well-being change but were found to moderate (e.g., amplify) the disparities in change attributed to individual variables. Our results suggest that resource-poor counties provide relatively less fertile grounds for successful aging until the end of life and may serve to exacerbate disparities. We conclude that examinations of how individual and residential characteristics interact can further our understanding of individual psychological outcomes and suggest routes for future inquiry.
\end{abstract}

Keywords: neighborhoods, selective mortality, successful aging, well-being, longitudinal methods

Life-span psychological and life course sociological perspectives have long proposed that individual development both actively influences and is influenced by contextual factors (Baltes, 1987; Bronfenbrenner, 1979; Lawton, 1982; Lerner, 1991; Magnusson \& Cairns, 1996; Verbrugge \& Jette, 1994). Consistent with these proposals, empirical research has produced a substantial body of evidence that, net of individual factors, community-level characteristics such as socioeconomic disadvantage or violence are indeed linked with individuals' functional health, well-being, and mortality (Argyle, 1999; Balfour \& Kaplan, 2002; Kawachi \& Berkman, 2003; Krause, 2003; Marmot \& Wilkinson, 1999; Ross \& Mirowsky, 2001; Sampson, Morenoff, \& Gannon-Rowley, 2002; Silver, Mulvey, \& Swanson, 2002). It is an open question, however, whether and how community and geographic factors relate to between-person differences in the progression of wellbeing, particularly at the end of life. In the current study, we applied three-level growth curve models to 24-year longitudinal data on life satisfaction, a key component of well-being, obtained
This article was published Online First August 2, 2010.

Denis Gerstorf and Nilam Ram, Department of Human Development and Family Studies, Pennsylvania State University; Max Planck Institute for Human Development, Berlin, Germany; and German Socio-Economic Panel Study, DIW Berlin (German Institute for Economic Research), Berlin, Germany; Jan Goebel, German Socio-Economic Panel Study, DIW Berlin; Jürgen Schupp, German Socio-Economic Panel Study, DIW Berlin, and Institute for Sociology, Free University of Berlin, Berlin, Germany; Ulman Lindenberger, Max Planck Institute for Human Development, Berlin, Germany; and Gert G. Wagner, Max Planck Institute for Human Development, Berlin, Germany; German Socio-Economic Panel Study, DIW Berlin; and Institute for Economics and Business Law, Berlin University of Technology, Berlin, Germany.
We are grateful for the support provided by the National Institute on Aging (Grants RC1-AG035645, NIA R21-AG032379, and NIA R21-AG033109); the DIW Berlin; the Max Planck Institute for Human Development, and the Social Science Research Institute at The Pennsylvania State University. Specific support was provided by Grant BMBF-DLR 01UW0706 from the Bundesministerium für Bildung und Forschung (Federal Ministry for Education and Research, Berlin, Germany) to Jürgen Schupp and Gert G. Wagner. The content of the article is solely the responsibility of the authors and does not necessarily represent the official views of the funding agencies.

Correspondence concerning this article should be addressed to Denis Gerstorf, Department of Human Development and Family Studies, 118 Henderson Building, The Pennsylvania State University, University Park, PA 16802. E-mail: gerstorf@psu.edu 
from now deceased participants of the German Socio-Economic Panel Study (SOEP; $N=3,427$; age at death $=18$ to 101 years) and asked two sets of questions about the role of residential environments for late-life well-being. First, we examined the extent of region-level differences in trajectories of late-life wellbeing and provided a quantification of the size of these differences. Second, we explored whether and how individual-level and regional-level factors are related to between-person differences in late-life trajectories of well-being.

Throughout adulthood and old age, levels of well-being appear to remain relatively stable (Diener, Lucas, \& Scollon, 2006; Diener, Suh, Lucas, \& Smith, 1999; Kunzmann, Little, \& Smith, 2000). In recent years, however, evidence has accumulated that, toward the very end of life, well-being declines considerably (Gerstorf, Ram, Estabrook, et al., 2008a; Gerstorf, Ram, Röcke, Lindenberger, \& Smith, 2008; Mroczek \& Spiro, 2005; Palgi et al., 2010). For example, Gerstorf et al. (2010) reported from national samples of decedents in Germany, the United Kingdom, and the United States that, on average, well-being was relatively stable over age but declined rapidly with impending death. These national-level replications are in line with long-standing conceptual notions that the end of life is typically foreshadowed by a phase of precipitous decline (Kleemeier, 1962; Riegel \& Riegel, 1972). However, there are substantial interindividual differences in how late-life well-being progresses. Thus far, the factors that contribute to this heterogeneity are poorly understood. Our objective in this study was to examine how a variety of individual and contextual factors may contribute to the differences we observe in late-life change trajectories of well-being.

\section{Individual Factors and Trajectories of Well-Being}

At the individual level, age, gender, education, and income each can be expected to be associated with between-person differences in well-being (Argyle, 1999; Diener et al., 1999). First, in consideration of age, several self-regulation theories (Brandtstädter, 1999; Brickman \& Campbell, 1971; Heckhausen \& Schulz, 1995) have suggested that the adaptive system is highly efficient throughout adulthood and old age in helping people adapt to a variety of (changes in) life circumstances. For example, socioemotional selectivity theory holds that with age-related limitations in perceived lifetime, people become increasingly skilled at optimizing their emotion regulation (Carstensen, 2006). As a consequence, objective declines in life conditions in old age (e.g., health constraints or social losses) do not affect average levels of well-being. Older people are typically as happy as (if not happier than) younger adults. In advanced ages, however, it appears as though the accumulated vulnerability, unpredictability, and biocultural constraints bring a sharp end to the possibilities afforded by the system of self-protective processes (Baltes \& Smith, 2003). In line with such a view, empirical reports suggest that persons dying after age 85 years show much steeper well-being decline with approaching death than do persons dying between 70 and 84 years (Gerstorf, Ram, Estabrook, et al., 2008; Gerstorf, Ram, Röcke, et al., 2008).

Gender-linked inequalities also have long been acknowledged in the life span and gerontological literature (for an overview, see Moen, 1996). For example, life course sociological theories contend that lifetime status and opportunity disadvantages follow current cohorts of women into old age and continue to reveal lasting negative effects into the last years (Elder, 1998; cf. Smith \& Baltes, 1998). In a similar vein, gender differentials in morbidity and mortality patterns create a scenario where life conditions in old age are typically very different between genders. Women typically experience more debilitating diseases than do men (Crimmins, 2001) and often have to deal with late-life challenges as widows, whereas older men are often still married and able to draw resources from their partners (see Suzman, Willis, \& Manton, 1992; Turner \& Troll, 1994). On the basis of these considerations, one can expect that the years prior to death may be more difficult to deal with for women as compared with men. Finally, education and income may also play a role for late-life well-being. The central argument here is that persons with lower education and/or income may have fewer resources to deal with late-life challenges and thereby be faced with increased risks of well-being declines (Diener et al., 1999).

\section{Context Factors and Trajectories of Well-Being}

Theoretical accounts of developmental contextualism propose that individuals live in contexts that provide both affordances and limitations for individual development (Baltes, 1987; Elder, 1974; Lerner \& Kauffman, 1985; Magnusson, 1996; Riley, 1987). One branch of this perspective has focused on the importance of environmental factors that shape people's daily experiences, including views on the human ecology (Bronfenbrenner, 1979), environmental gerontology (Lawton, 1982), environmental psychology (Wohlwill, 1970), and social disorganization (Faris \& Dunham, 1939; Sampson, Raudenbush, \& Earls, 1997). The common theme of these somewhat diverse perspectives is that macro-level contextual factors shape the nature and course of processes occurring at the individual level. This basic conceptual argument maps onto empirical reports documenting, for example, that older adults residing in disadvantaged neighborhoods experience more physical health problems, pursue less active lifestyles, and report lower levels of well-being (Aneshensel et al., 2007; Browning \& Cagney, 2003; Krause, 1996; Wen, Hawkley, \& Cacioppo, 2006; for an overview, see Yen, Michael, \& Perdue, 2009). In a similar vein, data from national samples in Australia (Shields, Price, \& Wooden, 2009) and the United Kingdom (Propper et al., 2005) suggested that neighborhood effects account for considerable portions of interindividual differences in reports of life satisfaction.

Our objective in this study was to extend this previous crosssectional work on (older) adults into the last years of life and to target questions about developmental change and the role that context factors may play in the rapid deteriorations in late-life well-being. For the end of life, tenets of life-span psychology (Baltes, 1997) suggest that as individuals age, there is an increasing need for cultural resources (such as supportive environments) that can help compensate for and adjust to the increasing biogenetic incompleteness of human life (as manifested in health constraints and other ailments). In a similar vein, Lawton's (1990) environmental docility hypothesis posits that environmental features become increasingly important as personal competencies decline. That is, prototypical health declines and losses render the person-context system particularly vulnerable and fragile at the very end of life. We thus expect that differences in the contextual environment will contribute significantly to differences in how 
people are able to adapt to late-life developments and to the progression of late-life well-being.

Examinations of the influence of ecological contexts range from more micro-level (proximal) features of one's residence to more macro-level (distal) characteristics of one's neighborhood, city, or county, all of which have been shown to profoundly affect people's daily lives, adaptive capabilities, attitudes, and behaviors (for an overview, see Leventhal \& Brooks-Gunn, 2000; Robert, 1999; Sampson et al., 2002; Wahl \& Lang, 2004). ${ }^{1}$ In the current study, we examine how county-level characteristics, as proxy for people's distal residential environment, are related to interindividual differences in the developmental progression of late-life wellbeing. We choose the county as the contextual unit for a number of reasons (see also Diehr et al., 1993; C. Hart, Ecob, \& Smith, 1997; Jürges, 2009; Matteson, Burr, \& Marshall, 1998; Rehdanz \& Maddison, 2009; Tesch-Roemer, Motel-Klingebiel, \& Huxhold, 2009), including data availability and tracking of units across time. Substantively, over and above these methodological constraints, counties constitute an important unit for defining localities. Counties provide administrative and political structures that are inherently linked with quantitative and qualitative characteristics of institutions and services (e.g., local welfare arrangements, public health service, ambulatory care nursing, public transportation, municipal garbage collection) that, in turn, relate to individuallevel outcomes. For example, inadequate public transportation may impose a high level of daily strain on residents and detrimentally affect their daily routines. In contrast, improving walkability by adding and maintaining barrier-free sidewalks and pedestrian amenities or clustering residential living areas near retail stores can be expected to positively affect quality of life and well-being. Moreover, federal and state governments often use counties as the unit of resource allocation, which may have substantive implications for the lives of their residents (e.g., communal family police, number of senior citizens centers, and health promotion programs). For example, through taxes and legislation, counties can undertake collective actions that provide health-promoting public goods for its residents, such as subsidizing health care or municipal centers and promoting access to local services and amenities (Kim, Subramanian, Gortmaker, \& Kawachi, 2006). All of these reasons contribute to creating differential regional settings for how the processes that influence the health of residents unfold (cf. Subramanian, Kubzansky, Berkman, Fay, \& Kawachi, 2006). We note that whereas more proximal features of individuals' residential environment (e.g., block or census tract) may have greater influence, distal features may also affect individual development outcomes.

Conceptual arguments linking county-level factors to betweenperson disparities in the progression of late-life well-being have primarily advanced the importance of various service, physical, and social environments. To begin with, institutional resources including the quantity, quality, density, availability, and accessibility of services can be expected to be of profound importance for promoting a healthy environment and for accommodating people's needs (Leventhal \& Brooks-Gunn, 2000). For example, counties with low average income and high rates of unemployment are typically faced with the challenges associated with a shortage of business taxes, on the one hand, and an excess of welfare expenses, on the other hand. In turn, these factors may impose sizable limitations on investments into provision of county-level services and institutions that are of direct or indirect health relevance, including the support for social programs or the availability and accessibility of health and long-term care facilities (e.g., fees and ancillary costs).

Another line of reasoning posits that physical environments are crucial for health and well-being (see Beard et al., 2009; Clarke \& George, 2005; Lawton, 1982; Verbrugge \& Jette, 1994; Wahl, 2001). For example, socioeconomically disadvantaged areas may be related not only to excessive levels of noise, pollution, accidents, and stress (see Krause, 1996) but also to conditions of the built environment. More specifically, less economically viable counties may not be able to repair dilapidated sidewalks or install elevators when needed, which in turn imposes greater risks that functional and mobility limitations, such as problems to walk, will result in disability. A third perspective highlights the role of the social environment and mechanisms tied to social cohesion and collective efficacy (see Bandura, 1986; Sampson et al., 1997; Thompson \& Krause, 1998). For example, socioeconomically deprived areas are often faced with challenges such as residential instability, various forms of incivility (e.g., criminal victimization), or prevailing social mistrust, all of which undermine social integration, positive affiliations with others, and an engaging community culture. In turn, such lack of social ties can be expected to have either direct implications for the progression of well-being and health or indirect implications, probably through a shortage of social support in the wake of chronic strains and negative life events (see Berkman, Glass, Brisette, \& Seeman, 2000; Cacioppo, Hughes, Waite, Hawkley, \& Thisted, 2006; Cohen \& Wills, 1985; House, Landis, \& Umberson, 1988; Seeman, 2001).

The general idea is that the various service, physical, and social characteristics of a given county may promote or hinder the striving of individuals toward maintaining adaptation and quality of life into the last years of life. We argue that individuals late in their lives are particularly susceptible to these effects of residential environments, probably because health constraints and mobility limitations can necessitate a greater reliance and dependency on municipal resources and services. More specifically, environments may serve as resources or constraints for an individual's action potential and either support or restrict the activities from which he or she directly or indirectly derives well-being. Notions of personenvironment fit (for a discussion, see Wahl \& Lang, 2004), for example, suggest that well-being may be at risk for decline if environmental resources do not sufficiently help to fulfill personal needs and to support remaining individual competencies. In contrast, people living and dying in more affluent environments may rely on structural advantages to maintain everyday routines and well-being into the last phases of life although functional limitations increasingly challenge their adaptive capabilities. One could also argue that contextual arrangements may similarly facilitate or

\footnotetext{
${ }^{1}$ Nomenclature and specific definitions differ between the various areas of study, and important distinctions are often made in the various disciplines (e.g., communities vs. neighborhoods). In the current study, we focus primarily on the common feature of these approaches to highlight that characteristics of the broad residential area in which people are living and dying are important for individual-level outcomes. We thus decided to primarily use the more generic term effects of the residential or regional environment but also to use this term interchangeably with neighborhood effects or community effects.
} 
threaten feelings of safety and familiarity, one's beliefs of control, and one's maintenance of a sense of continuity and meaning, all of which constitute central sources of stability or vulnerability to decline in well-being (Lachman, 2006). Finally, it is also possible that the long-term experience of accumulated stress and limited resources of poorer environments may corrode the mental and physical health of residents and thereby render them more vulnerable to late-life declines in well-being (Ellen, Mijanovich, \& Dillman, 2001). In our study, we focus on two sets of domains that have provided the most robust region-level effects in the extant literature and that may be of major relevance for late-life wellbeing and its progression. To index these characteristics, we follow earlier work (for an overview, see Leventhal \& Brooks-Gunn, 2000; Robert, 1999; Sampson et al., 2002) and make use of established and available markers of county-level wealth (gross domestic product and the rate of unemployment in the county) and health-care accessibility (number of medical doctors).

Finally, drawing from Lawton's (1990) environmental docility notion, we expect that the implications of regional factors for mental health outcomes may depend on individual-level factors. One possible scenario for such moderator or interaction effects between individual and regional factors may be that differences between sociodemographic strata are exacerbated in socioeconomically deprived counties. For example, individual resources may compensate for scarce regional resources or obstacles (e.g., lack of transportation) that prevent access to resources. However, if individual resources are scarce as well, compensation may no longer be possible.

\section{Aims of the Present Study}

In sum, the conceptual rationale for our study is that individuals' lives are embedded within communities and that the characteristics of these communities may have an influence on how individuals' well-being develops in the last years of life. To empirically address this notion, we combined individuallevel 24-year longitudinal data obtained from 3,427 participants in the national SOEP study with county-level data published by governmental offices. In a first step, we quantify how much variance in between-person differences in level and change of late-life well-being can be accounted for by county-level information. In a second step, we target select individual (age at death, gender, education, and household income) and county characteristics (wealth, rate of unemployment, and health-care access) and specifically examine their additive and interactive effects for the prediction of differences in individuals' wellbeing trajectories. Broadly following work in other areas (e.g., Sampson et al., 1997), we expect that individuals living and dying in structurally disadvantaged communities will report lower levels of well-being and experience steeper late-life declines in well-being. Further, we expect that differences between individuals will be magnified in these disadvantaged contexts.

\section{Method}

We applied three-level growth curve models to longitudinal data obtained from decedents of the SOEP. Comprehensive information about the larger household panel study is reported in Wagner,
Frick, and Schupp (2007). A brief overview of details relevant to the present analysis is given below.

\section{Participants}

The SOEP is a nationally representative annual national panel study of private households covering approximately 40,000 residents of former West and East Germany, including immigrants and resident foreigners. Potential participants were drawn at random from a set of randomly selected geographic locations in Germany. Relatively high initial response rates (between $60 \%$ and $70 \%$ ) and low longitudinal attrition (about $15 \%$ for the second wave and less than $5 \%$ yearly attrition across various subsamples) provide for an overall sample representative of the population living in private households (Kroh, Pischner, Spieß, \& Wagner, 2008; Kroh \& Spieß, 2006) and long-term care homes in Germany (Klein, 1996). Data were primarily collected through face-to-face interviews, with the exception that about $10 \%$ of individuals who had already participated several times provided data by self-administered questionnaires.

With an interest in end-of-life processes, we made use of the SOEP's continuous tracking of participants through to their deaths. Mortality status and date of death for deceased participants is obtained at the yearly interviews, either directly from the remaining household members or neighbors or from official registries. In total, the death rates and ages of death of participants of the SOEP parallel official life tables and serve as a representative resource for mortality-related analyses in Germany (e.g., Brockmann \& Klein, 2004; Burkhauser, Giles, Lillard, \& Schwarze, 2005). We used data obtained from the 3,427 participants who had (a) died prior to May 2009, (b) provided at least one rating of life satisfaction during the last 10 years of their lives, and (c) provided data on all individual-level predictors (e.g., gender, income).

These decedents were born between 1888 and 1987 and died between 18 and 101 years later (average age at death $=73.35$, $S D=14.41$ ), sometime between 1986 and 2009. As expected, when compared with participants who were still living, the deceased subsample was, on average, older $(M=64.05$ years, $S D=$ 15.07 , vs. $M=37.91, S D=17.08), F(1,43,244)=7,526.80, p<$ $.001, R^{2}=.148$; included slightly more men (51\% vs. $\left.49 \%\right)$, $\chi^{2}(1, N=43,248)=5.72, p<.05$; reported lower levels of life satisfaction $(M=6.95, S D=2.33$, vs. $M=7.45, S D=1.84)$, on a scale ranging from 0 (totally unsatisfied) to 10 (totally satisfied), $F(1,43246)=217.05, p<.001, R^{2}=.005$; had fewer years of education $(M=10.69, S D=2.12$, vs. $M=11.36, S D=2.74)$, $F(1,39404)=190.13, p<.001, R^{2}=.005$; and received a lower net annual household income, $(M=21,559.20, S D=15,773.56$, vs. $M=31,802.02, S D=29,423.09), F(1,43,090)=405.25, p<$ $.001, R^{2}=.009$. Respondents in our now deceased sample participated in an average of $8.23(S D=6.00)$ assessments, with $80 \%$ contributing data on three or more occasions. On average, deaths occurred 9.30 years $(S D=6.05$; range $=1-24$ years $)$ after participants' initial assessment and 2.07 years $(S D=2.12$; range $=0-10$ years) after their last assessment. Participants contributed a total of 27,823 observations that span the 24 to 0 years ( $M=7.64, S D=5.24)$ prior to death. The majority of these observations, $73 \%$, were provided in the last 10 years of life. A total of 2,853 participants, or $83 \%$, of the deceased sample had 
provided data on life satisfaction in the last three years of life. We also examined whether and how these participants differed from those who had dropped out earlier. These analyses revealed that participants who remained in the study until three years prior to death reported somewhat higher life satisfaction at four years prior to death $(45.46$ vs. 43.36$), F(1,2329)=4.53, R^{2}=.002$; were younger (72.58 vs. 77.19 years), $F(1,3425)=49.55, R^{2}=.014$; received higher incomes (19.70 vs. 21.93), $F(1,3425)=9.57$, $R^{2}=.003$, and were more likely to be men (52\% vs. $\left.48 \%\right), \chi^{2}(1$, $N=3,427)=9.75$, all $p \mathrm{~s}<.05$, whereas no differences were found in education. Conjointly, this sample attrition pattern suggests that participants in the SOEP who had died at an older age, received less income, were women, and reported lower life satisfaction were less likely to remain in the study until close to death. As a consequence, we have probably slightly underestimated population-based rates of well-being decline late in life.

\section{Counties}

For an overview, Figure 1 shows the frequency of deceased participants from the SOEP per county across all of Germany. Participants cover almost the entirety of the 439 German counties. Our analyses included 412 distinct regions covering 417 counties (95\% of all counties), in which $98.04 \%$ of all people in Germany live (reference year 2006). The slight discrepancy was due to administrative changes in county borders over time (e.g., especially in East Germany after German reunification) and our need for correct correspondence over time. As one would expect, counties not represented in the SOEP were primarily the smallest counties (e.g., average number of inhabitants in 2006: in all German counties $=187,600$; in counties included in our analysis $=193,700$; in counties not included in our analysis $=$ 73,280 ). A given county was represented by an average of 8.32

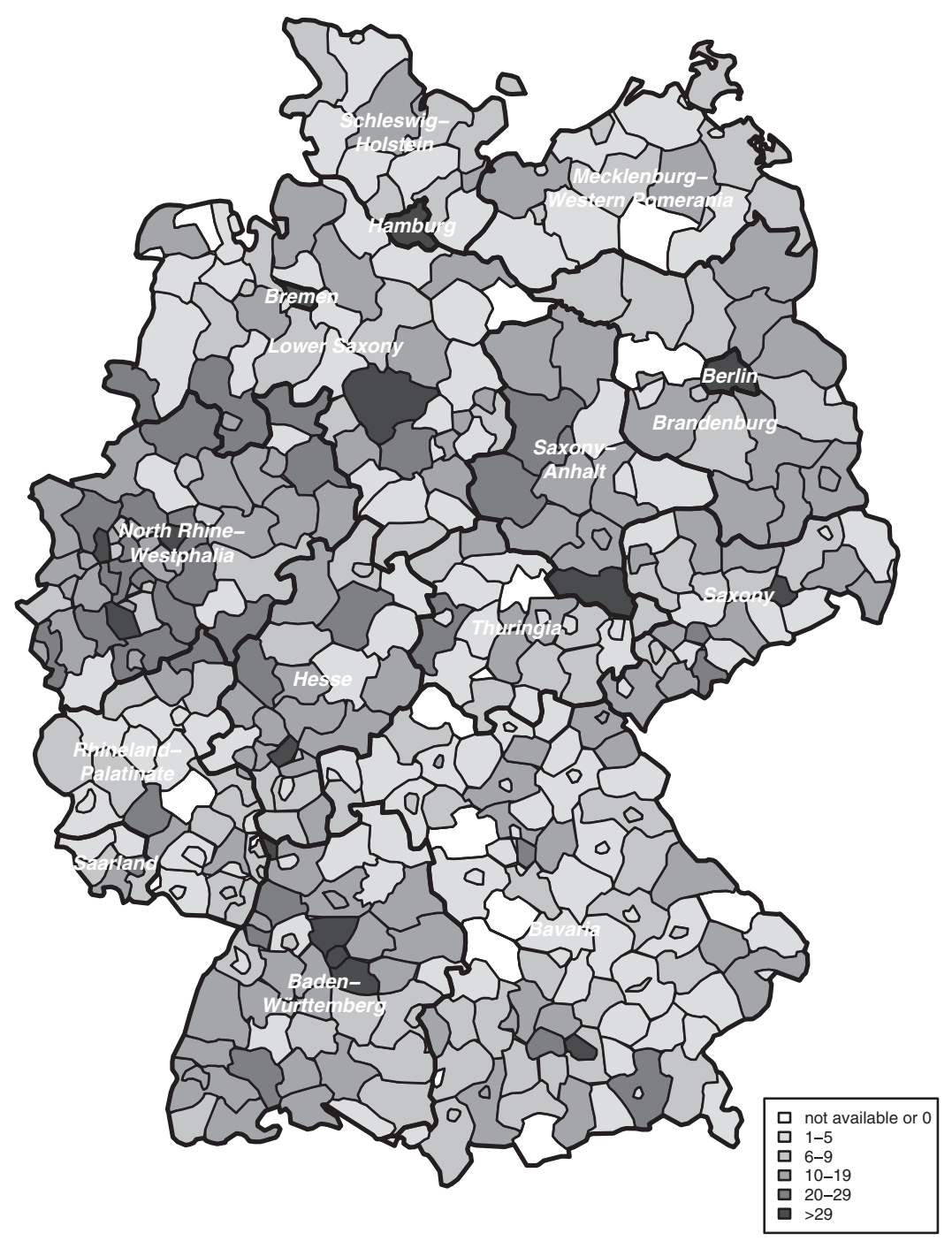

Figure 1. Frequency of deceased participants in the Socio-Economic Panel Study per county across all of Germany. Participants cover almost the entirety of the 412 German counties. A given county was represented by a mean of 8.32 participants $(S D=9.06$, minimum $=1$, maximum $=114, M d n=6)$. 
participants $(S D=9.06$, minimum $=1$, maximum $=114$, $M d n=6)$.

\section{Measures}

Life satisfaction. As a measure of life satisfaction, we used responses to the question "Wie zufrieden sind Sie gegenwärtig, alles in allem, mit ihrem Leben?" (translated as, "How satisfied are you with your life concurrently, all things considered?"), answered on a scale ranging from 0 (totally unsatisfied) to 10 (totally satisfied). This item is considered a measure of cognitiveevaluative (as opposed to emotional) aspects of well-being and has been widely used in psychological research (e.g., Fujita \& Diener, 2005; Gerstorf, Ram, Estabrook, et al., 2008; Lucas, Clark, Georgellis, \& Diener, 2003). We standardized responses from our deceased subsample to the larger, nationally representative SOEP sample. Specifically, responses were standardized to a $T$ metric $(M=50, S D=10)$, with the mean and standard deviation of responses available from the entire sample from the longitudinal study at their first measurement occasion as the reference frame $(N=42,842: M=7.42, S D=1.88)$. Further details about measurement properties of the life satisfaction measure as used in the SOEP can be obtained from Fujita and Diener (2005), Schilling (2006), and Schimmack, Schupp, and Wagner (2008).

Individual-level factors. Four individual-level variables were used as time-invariant predictors of between-person differences in trajectories of well-being: age at death, gender, years of education, and income. Given some nonlinearity in its relationship with other variables, age at death was coded as a three-category grouping variable: Individuals who died before reaching age 70 years $(n=$ $1,151)$, those who died when between 70 and 79 years $(n=972)$, and those who died after reaching the age of 80 years $(n=1,304)$. From individuals' most recent reports, we defined years of completed education as the minimum number of years an individual needed to acquire his or her particular degree $(M=10.69, S D=$ 2.12) and income as the net (i.e., posttax) annual household income $(M=21.56, S D=15.77$, in thousands of Euro).

County-level factors. County-level data were obtained from the official published statistics of the German Federal Office for Building and Regional Planning as the superior federal authority in the operational division of the Federal Ministry of Transport, Building and Urban Affairs (see http://www.bbr.bund.de/cln_016/EN). Gross domestic product (GDP) was calculated as the value of material goods produced annually per inhabitant in a given county (in thousands of Euro). Rate of unemployment was calculated as the number of unemployed persons relative to the total number of persons who are entitled to work. Number of medical doctors was calculated as the number per 100,000 inhabitants. The 412 counties used here had an average GDP of 24.44 thousand Euro $(S D=10.18$, range $=10-83$ ), 10.91 unemployed persons per 100 eligible workers $(S D=5.31$, range $=2-31)$, and 143.65 doctors per 100,000 inhabitants $(S D=$ 46.76 , range $=66-391$ ). The two indicators of county-level wealth of gross domestic product and the rate of unemployment were moderately intercorrelated $(r=-.20, p<.001)$, suggesting both conceptual and analytical distinction.

County-level data were available for the years 1995 to 2004 for GDP, 1985 to 2005 for the rate of unemployment, and 1993 to 2004 for the number of medical doctors. Year-to-year rank-order stabilities were very high ( $r=.89$ or higher), suggesting that counties largely maintained their relative position within Germany and that the measures can justifiably be used as time-invariant predictors. Given that our primary interest concerned well-being at the end of life, we tied county-level data to individual-level data using, if available, the federal statistics for the year prior to an individual's death $(65 \%$ for the county's GDP, $91 \%$ for the rate of unemployment, and $58 \%$ for the number of medical doctors in the county). Otherwise, data were taken from the year closest to an individual's year of death. This linking procedure meant that county-level reports consisted of descriptions of the context in which a person was living a few years prior, on average, to their death (GDP: $M=2.08, S D=3.16$; rate of unemployment: $M=0.09, S D=0.29$; and number of medical doctors: $M=1.50, S D=2.40$ ).

\section{Data Structure}

Table 1 provides descriptive statistics for life satisfaction over time to death. We note that life satisfaction observations that are taken far from the time of death are, on average, relatively close to the mean of the reference sample (e.g., $M=48.92$ at 17 years prior to death), whereas average levels decrease with proximity to death (e.g., $M=$ 40.65 at the year prior to death). Using the accelerated longitudinal design, we treated all data segments as representing a single sample, which allowed for estimating a time-to-death gradient over the period of up to 24 years. Given that change effects are derived from all longitudinal segments under the missing-at-random assumption (Little \& Rubin, 1987), more weight is implicitly given to information

Table 1

Descriptive Statistics for Life Satisfaction Over Time to Death

\begin{tabular}{crrr}
$\begin{array}{c}\text { Time-to-death } \\
\text { (in years) }\end{array}$ & $n$ & $M$ & $S D$ \\
\hline 23 & 75 & 50.53 & 12.13 \\
22 & 152 & 50.99 & 11.37 \\
21 & 232 & 49.94 & 11.24 \\
20 & 309 & 50.11 & 10.65 \\
19 & 379 & 49.48 & 10.93 \\
18 & 434 & 50.18 & 10.60 \\
17 & 521 & 48.92 & 11.30 \\
16 & 613 & 48.45 & 10.83 \\
15 & 715 & 48.80 & 10.66 \\
14 & 833 & 48.70 & 10.41 \\
13 & 954 & 48.37 & 10.85 \\
12 & 1,090 & 47.60 & 11.04 \\
11 & 1,258 & 47.55 & 11.01 \\
10 & 1,393 & 47.62 & 11.22 \\
9 & 1,523 & 47.54 & 11.18 \\
8 & 1,626 & 46.69 & 11.26 \\
7 & 1,827 & 46.66 & 11.35 \\
6 & 1,995 & 46.34 & 11.21 \\
5 & 2,203 & 45.91 & 11.62 \\
4 & 2,331 & 45.33 & 11.80 \\
3 & 2,437 & 44.78 & 12.10 \\
2 & 2,511 & 43.73 & 12.66 \\
1 & 2,379 & 40.65 & 13.54 \\
0 & 13 & 40.40 & 12.76 \\
\hline
\end{tabular}

Note. $\quad N=3,427$ participants who provided 27,823 observations. Scores were standardized to a $T$ metric $(M=50, S D=10)$ with the mean and standard deviation of responses available from the entire SOEP sample at their first measurement occasion as the reference frame $(N=42,842: M=7.42$, $S D=1.88)$. 
obtained from those individuals who provided the most change (i.e., most occasions) information. ${ }^{2}$ We fit models to the data using SAS (Proc Mixed; Littell, Miliken, Stoup, \& Wolfinger, 1996).

\section{Statistical Analysis}

Individual-level and county-level differences in change. Our first task was to obtain estimates of the extent of differences among well-being trajectories and to determine what proportion of those differences were county-level differences. To accomplish this, we conducted a series of growth curve models. First, we constructed a standard growth model (see Ram \& Grimm, 2007; Raudenbush \& Bryk, 2002; Singer \& Willett, 2003), where the repeated occasions are nested within individuals. This model was specified as

$$
\text { satisfaction }_{t i c}=\beta_{0 i c}+\beta_{1 i c}\left(t t d_{t i c}\right)+\beta_{2 i c}\left(t t d_{t i c}\right)^{2}+e_{t i c},
$$

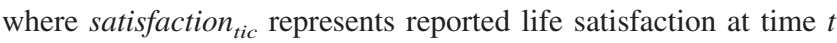
for individual $i$ nested within county $c$, as a function of an individual-specific intercept; $\beta_{\text {Oic }}$, an individual-specific linear slope; $\beta_{1 i c}$, which captures the linear rate of change over time to death $(t t d)$; an individual-specific quadratic slope, $\beta_{2 i c}$, which captures the extent of quadratic curvature over time-to-death $\left(t t d^{2}\right)$, and a time-specific residual, $e_{t i c}$. Individual-specific intercepts, $\beta_{\text {Oic }}$, linear slopes, $\beta_{1 i c}$, and quadratic slopes, $\beta_{2 i c}$ (from the Level 1 model given in Equation 1) were modeled at Level 2 as

$$
\begin{aligned}
& \beta_{0 i c}=\gamma_{00 c}+u_{0 i c}, \\
& \beta_{1 i c}=\gamma_{10 c}+u_{1 i c}, \text { and } \\
& \beta_{2 i c}=\gamma_{20 c},
\end{aligned}
$$

where $\gamma_{00 c}, \gamma_{10 c}$, and $\gamma_{20 c}$ were county-level parameters and $u_{0 i c}$ and $u_{1 i c}$ were individual deviations. These between-person differences were assumed to be multivariate normally distributed, correlated with each other, and uncorrelated with all other residuals. Of specific interest was the extent of between-person differences in the two aspects of individual trajectories: the intercept (variance of $u_{0 i c}$ ) and linear slope (variance of $u_{1 i c}$ ). Ignoring, for the moment, the county-level nesting, we made note of these betweenperson variances.

We then expanded the model to accommodate the fact that individuals were nested within counties. Adding Level 3, we modeled county-specific intercepts, $\gamma_{00 c}$; linear slopes, $\gamma_{10 c}$; and quadratic slopes, $\gamma_{20 c}$; as

$$
\begin{aligned}
& \gamma_{00 c}=\pi_{000}+\nu_{00 c}, \\
& \gamma_{10 c}=\pi_{010}+\nu_{01 c}, \text { and } \\
& \gamma_{20 c}=\pi_{020},
\end{aligned}
$$

where $\pi_{000}, \pi_{010}$, and $\pi_{020}$ were sample means, and $v_{00 c}$ and $v_{01 c}$ were county deviations from those means. These between-county differences were assumed to be multivariate normally distributed, correlated with each other, and uncorrelated with all other residuals.

Our interest in this model was to determine the proportion of between-person differences in intercept and linear slope found in the previous step that were now attributed to county-level differences. Following the logic and use of the intraclass correlation for quantify- ing the relative proportion of between- and within-person variance in multilevel models, we quantified the relative proportion of betweenperson and between-county variance in two aspects of individuals' well-being trajectories: intercept and linear slope. Specifically, we compared the amount of between-person differences in both level and linear change at Level 2 between the two models and determined the proportion of the between-person differences in the two-level model attributable to between-county differences in the three-level model.

Individual- and county-level predictors of change. In the final step, we explored whether and how the noted between-person and between-county variance in individuals' life-satisfaction trajectories was related to the specific individual-level and countylevel variables noted above. The growth model was again expanded, this time by adding predictors at both the individual and county levels (Levels 2 and 3). The Level 2 model took the following form:

$$
\begin{aligned}
& \beta_{0 i c}=\gamma_{00 c}+\gamma_{01 c}\left(\text { age at death }{ }_{i c}\right)+\gamma_{02 c}\left(\text { gender }_{i c}\right) \\
& +\gamma_{03 c}\left(\text { education }_{i c}\right)+\gamma_{04 c}\left(\text { income }_{i c}\right)+u_{0 i c},
\end{aligned}
$$

and

$$
\begin{aligned}
& \beta_{1 i c}=\gamma_{10 c}+\gamma_{11 c}(\text { age at death } i c)+\gamma_{12 c}\left(\text { gender }_{i c}\right) \\
& +\gamma_{13 c}\left(\text { education }_{i c}\right)+\gamma_{14 c}\left(\text { income }_{i c}\right)+u_{1 i c},
\end{aligned}
$$

and the Level 3 model was specified as the following:

$$
\begin{aligned}
& \gamma_{00 c}=\pi_{000}+\pi_{001}\left(G D P_{c}\right)+\pi_{002}\left(\text { unemployment }_{c}\right) \\
& +\pi_{003}\left(\text { health } \text { care }_{c}\right)+v_{00 c} \text {, }
\end{aligned}
$$

$\gamma_{01 c}=\pi_{010}+\pi_{011}\left(G D P_{c}\right)+\pi_{012}\left(\right.$ unemployment $\left._{c}\right)$

$$
+\pi_{013}\left(\text { health } \text { care }_{c}\right),
$$

$$
\ldots \text { (for } \gamma_{02 c}, \gamma_{03 c}, \gamma_{04 c} \text {, respectively). }
$$

$\gamma_{10 c}=\pi_{100}+\pi_{101}\left(G D P_{c}\right)+\pi_{102}\left(\right.$ unemployment $\left._{c}\right)$

$$
+\pi_{103}\left(\text { health }_{\text {care }}\right)+v_{10 c},
$$

$\gamma_{11 c}=\pi_{110}+\pi_{111}\left(G D P_{c}\right)+\pi_{112}\left(\right.$ unemployment $\left._{c}\right)$

$$
+\pi_{113}\left(\text { health } \text { care }_{c}\right),
$$

$\ldots$ (for $\gamma_{12 c}, \gamma_{13 c}, \gamma_{14 c}$, respectively).

\footnotetext{
${ }^{2}$ Applying the missing-at-random assumption means that our growth models produced estimates of average within-person change independent of whether an individual remained in the sample over time. We acknowledge that this is a strict assumption, for which the plausibility is at best unknown. The missing-at-random assumption allows for prior differences in level and observed change to predict subsequent participation, but it is violated when unobserved change differs from observed change. One can reasonably expect such a plausible scenario in that respondents who discontinue may have experienced stronger decline than those who continue participation. Although we have included attrition-informative variables in our models (age, gender, education, etc.) so as to enhance the effectiveness of the estimation algorithm in accommodating incomplete data, we acknowledge that our models give implicitly more weight to information obtained from the presumably positively selected individuals who provided the most change (i.e., most occasions) information.
} 
Of specific interest was the identification of the individual-level variables, county-level variables, and their interactions that were significant predictors of differences in how life satisfaction developed over time to death.

\section{Results}

\section{Individual and County Differences in Late-Life Well-Being}

Results from the two- and three-level growth models are given in Table 2. Consistent with our previous work on late-life changes in life satisfaction with the SOEP (Gerstorf, Ram, Estabrook, et al., 2008; Gerstorf et al., 2010), both models indicate a prototypical trajectory that is characterized by substantial decline (see fixed effects). On average, the linear component of decline amounted to almost a full standard deviation over the last 10 years of life $\left(\gamma_{10}=\right.$ -0.906), which together with some concave curvature $\left(\gamma_{20}=\right.$ -0.032 ) brought the average individual to a level of life satisfaction two years before death $\left(\gamma_{00}=43.155\right)$ that was 0.68 standard deviations below the mean of the reference sample $(M=50)$.

Of primary interest here, however, was the extent of individual differences in change, as indicated by the variance components (random effects). From the results of the two-level model we noted the extent of interindividual differences in two components of change. In particular, (total) variance of the intercept was $\sigma_{u 00}^{2}=$ 90.230, and variance in the linear slope was $\sigma_{u 01}^{2}=0.504$, both indicating significant variability in how life satisfaction develops late in life. In the three-level model, where it is acknowledged that individuals are nested within counties, the "total" variance in intercept and linear slope was decomposed into a portion that could be attributed to between-person differences and a portion that could be attributed to between-county differences. We found that a significant portion of variance in both intercept, $\sigma_{u 00 c}^{2}=$ 7.004 , and linear slope, $\sigma_{u 10 c}^{2}=0.042$, could be attributed to between-county differences. Quantified as an intraclass correlation $\left(\sigma_{\text {county }}^{2} / \sigma_{\text {total }}^{2}\right)$, the proportion of between-county variance was .077 in intercept and .083 in linear slope. That is, some $8 \%$ of the differences in the intercept could be attributed to differences among counties, with the remaining $92 \%$ being attributed to differences among persons. Similarly, approximately $8 \%$ of the differences in the linear slope could be attributed to differences among counties, with the remaining $92 \%$ being attributed to differences among persons. Taken together, these results suggest that there are substantial differences in how individuals' life satisfaction changes late in life, and that a notable portion of these differences may be attributed to differences among the geographic contexts in which people live and die.

\section{Individual and County Predictors of Differences in Late-Life Well-Being}

Having found that substantial differences in change exist among both individuals and counties, we explored whether and how various individual-level and county-level characteristics were related to those differences. To do so, we introduced a set of predictors into the three-level growth model. Nonsignificant inter-

Table 2

Growth Models for Life Satisfaction Over Time to Death in the Socio-Economic Panel Study, With and Without Modeling of Possible County-Level Effects

\begin{tabular}{|c|c|c|}
\hline \multirow[b]{2}{*}{ Variable } & \multicolumn{2}{|c|}{ Life satisfaction over time to death } \\
\hline & $\begin{array}{l}\text { Individual } \\
\text { variables }\end{array}$ & $\begin{array}{l}\text { Individual and } \\
\text { county variables }\end{array}$ \\
\hline \multicolumn{3}{|l|}{ Fixed effects } \\
\hline Intercept, ${ }^{\mathrm{a}} \gamma_{00}$ & $43.155^{*}(0.189)$ & $43.144^{*}(0.243)$ \\
\hline Linear slope, ${ }^{b} \gamma_{10}$ & $-0.906 *(0.034)$ & $-0.907^{*}(0.037)$ \\
\hline Quadratic slope, ${ }^{\mathrm{b}} \gamma_{20}$ & $-0.032^{*}(0.002)$ & $-0.032 *(0.002)$ \\
\hline \multicolumn{3}{|l|}{ Random effects: Individual level } \\
\hline Variance intercept, $\sigma_{\mathrm{uo0}}^{2}$ & $90.230^{*}(2.820)$ & $83.652 *(2.796)$ \\
\hline Variance linear slope, $\sigma_{\mathrm{u} 01}^{2}$ & $0.504^{*}(0.034)$ & $0.467 *(0.034)$ \\
\hline Covariance intercept, linear slope & $3.826^{*}(0.252)$ & $3.752 *(0.254)$ \\
\hline \multicolumn{3}{|l|}{ Random effects: County level } \\
\hline Variance intercept, $\sigma_{\mathrm{u} 00 \mathrm{c}}^{2}$ & & $7.004^{*}(1.525)$ \\
\hline Proportion of variance attributable to county differences & & $7.76 \%$ \\
\hline Variance linear slope, $\sigma_{\mathrm{u} 10 \mathrm{c}}^{2}$ & & $0.042^{*}(0.015)$ \\
\hline Proportion of variance attributable to county differences & & $8.33 \%$ \\
\hline Covariance intercept, linear slope & & $0.039(0.109)$ \\
\hline Residual variance & $65.806^{*}(0.627)$ & $65.771 *(0.626)$ \\
\hline$-2 L L$ & 204,058 & 203,971 \\
\hline$A I C$ & 204,072 & 203,991 \\
\hline
\end{tabular}

Note. Unstandardized estimates are presented, with standard errors in parentheses. The proportion of variance attributable to county differences for the variance intercept and variance linear slope are highlighted in boldface. A total of 3,427 participants nested within 412 counties provided 27,823 observations. Scores were standardized to a $T$ metric $(M=50, S D=10)$ from the mean and standard deviation of responses available from the entire Socio-Economic Panel Study sample at their first measurement occasion as the reference frame $(N=42,842: M=7.42, S D=1.88)$. AIC $=$ Akaike's information criterion; $-2 L L=-2 \log$ likelihood, relative model fit statistics.

${ }^{a}$ Intercept is centered at two years prior to death. ${ }^{\mathrm{b}}$ Slopes or rates of change are scaled in $T$ units per year.

$* p<.01$ 
action terms were trimmed for ease of presentation. Results from the final model are reported in Table 3.

Individual-level variables. Beginning with the individuallevel variables, results indicated significant associations of age and

Table 3

Growth Model for Life Satisfaction Over Time to Death in the Socio-Economic Panel Study Including Individual-Level and County-Level Factors: Unstandardized Estimates and Standard Errors

\begin{tabular}{|c|c|c|}
\hline Parameter & $\begin{array}{l}\text { Unstandardized } \\
\text { estimate }\end{array}$ & $S E$ \\
\hline \multicolumn{3}{|l|}{ Fixed effects } \\
\hline Intercept, $\gamma_{000}$ & $43.363^{*}$ & $(0.424)$ \\
\hline Linear slope, $\gamma_{100}$ & $-0.948^{*}$ & $(0.053)$ \\
\hline Quadratic slope, $\gamma_{200}$ & $-0.034^{*}$ & $(0.002)$ \\
\hline \multicolumn{3}{|l|}{ Individual level: Intercept } \\
\hline Died $\leq 69$ years & -0.993 & $(0.461)$ \\
\hline Died $70-79$ years & & \\
\hline Died $80+$ years & -0.594 & $(0.454)$ \\
\hline Gender $(0=$ women, $1=$ men $)$ & 0.706 & $(0.376)$ \\
\hline Education & $0.581^{*}$ & $(0.092)$ \\
\hline Income & 0.006 & $(0.012)$ \\
\hline \multicolumn{3}{|l|}{ Individual level: Linear slope } \\
\hline Died $\leq 69$ Years $\times$ Linear Slope & $0.143^{*}$ & $(0.052)$ \\
\hline Died $80+$ Years $\times$ Linear Slope & $-0.188^{*}$ & $(0.050)$ \\
\hline Gender $\times$ Linear Slope & 0.076 & $(0.042)$ \\
\hline Education $\times$ Linear Slope & $0.031^{*}$ & $(0.010)$ \\
\hline Income $\times$ Linear Slope & -0.003 & $(0.001)$ \\
\hline \multicolumn{3}{|l|}{ County level: Intercept } \\
\hline Gross domestic product (GDP) & $0.089^{*}$ & $(0.035)$ \\
\hline Rate of unemployment & $-0.162^{*}$ & $(0.042)$ \\
\hline Health care access & -0.016 & $(0.007)$ \\
\hline \multicolumn{3}{|l|}{ County level: Linear slope } \\
\hline GDP $\times$ Linear Slope & 0.006 & $(0.006)$ \\
\hline \multicolumn{3}{|l|}{ Rate of Unemployment $\times$ Linear } \\
\hline Slope & 0.008 & $(0.008)$ \\
\hline \multicolumn{3}{|l|}{ Health Care Access $\times$ Linear } \\
\hline Slope & -0.002 & $(0.001)$ \\
\hline \multicolumn{3}{|l|}{ Cross-level interactions } \\
\hline \multicolumn{3}{|l|}{ Rate of Unemployment $\times$ Linear } \\
\hline Slope $\times$ Education & $0.007^{*}$ & $(0.002)$ \\
\hline \multicolumn{3}{|l|}{ Health Care Access $\times$ Linear } \\
\hline \multirow{2}{*}{\multicolumn{3}{|c|}{ Random effects: Individual level }} \\
\hline & & \\
\hline Variance intercept, $\sigma_{\text {u0ic }}^{2}$ & $81.265^{*}$ & $(2.732)$ \\
\hline Variance linear slope, $\sigma_{\mathrm{u} 1 \mathrm{ic}}^{2}$ & $0.423^{*}$ & $(0.031)$ \\
\hline Covariance intercept, linear slope & $3.657^{*}$ & $(0.245)$ \\
\hline \multicolumn{3}{|l|}{ Random effects: County level } \\
\hline Variance intercept, $\sigma_{\mathrm{u} 00 \mathrm{c}}^{2}$ & $6.074^{*}$ & $(1.412)$ \\
\hline Variance linear slope, $\sigma_{\mathrm{u} 10 \mathrm{c}}^{2}$ & $0.031^{*}$ & $(0.013)$ \\
\hline Covariance intercept, linear slope & 0.093 & $(0.102)$ \\
\hline Residual variance & $65.835^{*}$ & $(0.626)$ \\
\hline$-2 L L$ & 203,723 & \\
\hline$A I C$ & 203,805 & \\
\hline
\end{tabular}

Note. Intercept was centered at two years prior to death; slopes were scaled in $T$ units per year. A total of 3,427 participants nested within 412 counties provided 27,823 observations. Scores were standardized to a $T$ metric $(M=50, S D=10)$ with the mean and standard deviation of responses available from the entire Socio-Economic Panel Study sample at their first measurement occasion as the reference frame $(N=42,842: M=$ $7.42, S D=1.88)$. Participants who died between the ages of 70 and 79 years served as the reference. Interaction effects not significant at $p<.01$ were omitted for clarity. $A I C=$ Akaike's information criterion; $-2 L L=$ $-2 \log$ likelihood, relative model fit statistics.

$* p<.01$ education with either the intercept or the linear change of wellbeing or with both. Specifically, more educated persons reported higher well-being at two years prior to death and also evinced less steep decline with approaching death. For age at death, we found that participants who died at advanced ages $(80+$ years $)$ showed, on average, steeper decline than individuals who died in their 70s, who in turn showed greater decline than individuals who died at earlier ages ( $\leq 69$ years). No significant effects were found for gender and income.

County-level factors. With regard to the county-level variables, we also found statistically reliable associations with levels of late-life well-being. Participants who had been living and dying in counties with higher GDP and lower rates of unemployment reported higher levels of well-being. As an illustration, Figure 2 shows that participants of the SOEP living in wealthy communities (i.e., GDP in the county $+1 S D$ ) reported higher life satisfaction throughout the final years of life than did participants living in less wealthy communities (i.e., GDP in the county $-1 S D$ ). We did not find predictive associations among any of the three regional factors examined and differential change in well-being but obtained two significant three-way interactions for rates of change and education - with the rate of unemployment and with health-care access.

Cross-level interactions. Follow-up analyses revealed that differences in well-being trajectories attributed to education effects were exacerbated in counties with sociostructural problems (i.e., high unemployment rate, little health-care access). For example, Figure 3 illustrates that in counties with low unemployment rates (i.e., - $1 S D$ ), high- and low-educated SOEP participants showed relatively minor differences in late-life level and change in life satisfaction (upper panel). In contrast, in counties with high unemployment rates (i.e., $+1 S D$ ), differences between education groups in both level and change in late-life well-being were magnified (lower panel). We obtained similar findings for the differences among counties with high and low levels of health-care access. Taken together, our results indicate that sociostructural characteristics of the living environment indeed relate to reports of well-being at the individual level. Such cross-level associations not only persist into the last years of life but also moderate individuallevel disparities.

\section{Discussion}

The objective of the current study was to explore whether where people live geographically and the associated regional structure and infrastructure characteristics make a difference in how people experience their last years of life. To conduct this exploration, we applied three-level growth curve models to 24-year longitudinal data of deceased participants in the national SOEP $(N=3,427$; age at death $=18$ to 101 years). In a first set of analyses, we identified the relative contribution of individual and regional factors to disparities in the progression of end-of-life well-being. Results indicated that some $8 \%$ of the between-person differences in both level and decline of well-being reflected between-county differences. In a second step, we explored the role of three regional factors of wealth, socioeconomic status, and health-care access to contribute to these inequalities. Our findings revealed that, over and above key individual predictors (age at death, gender, education, and income), living in wealthy communities was related to reports of higher late-life well-being. The regional factors exam- 


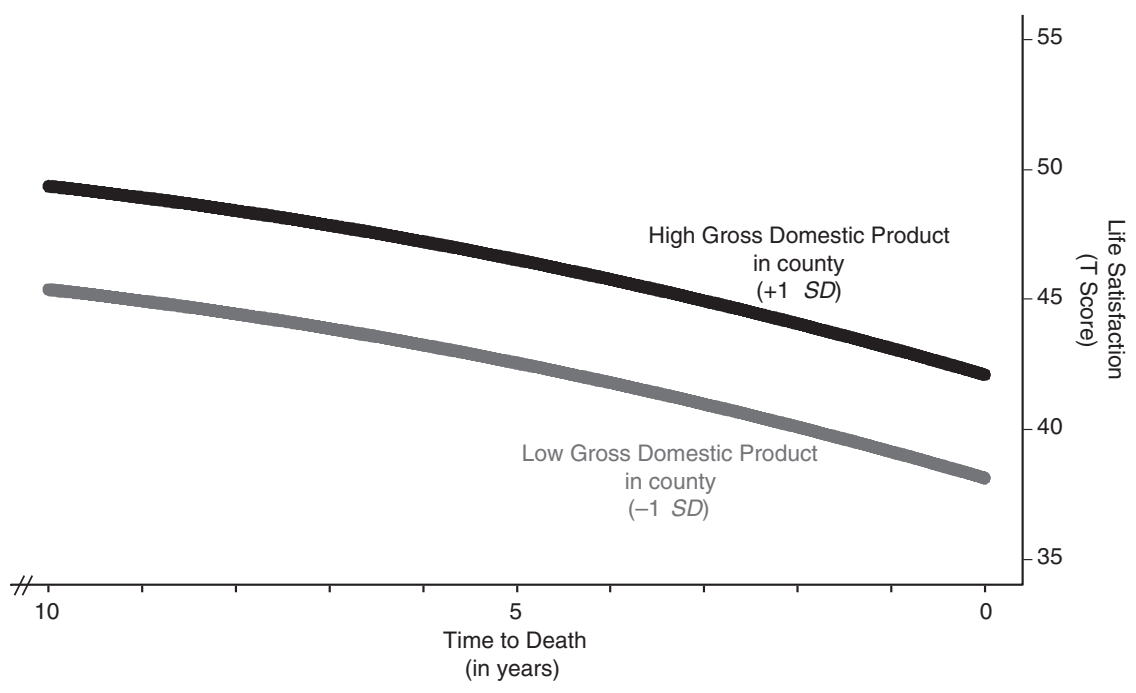

Figure 2. Illustration showing that community factors are related to individual differences in levels of late-life well-being. Socio-Economic Panel Study participants living in wealthy communities (i.e., Gross Domestic Product in the county $+1 S D$ ) reported higher life satisfaction throughout the final years of life than did participants living in less wealthy communities (i.e., Gross Domestic Product in the county $-1 S D$ ).

ined did not directly relate to well-being change but were found to moderate the predictive effects of individual factors for differential end-of-life change in well-being (e.g., amplified between-person disparities in less wealthy counties). Our results are consistent with long-standing life-span psychological notions that individual development is contextually embedded and suggest that examining regional and other context characteristics can further our understanding of individual psychological outcomes. We discuss possible underlying mechanisms and routes for future inquiries to substantiate our initial findings.

\section{Individual and County Differences in Late-Life Well-Being}

Profound associations between regional factors and individual outcomes have long been documented, with the likely most prominent reports linking poverty and crime in urban neighborhoods with the development of youth delinquency and violence (e.g., Sampson et al., 1997; Tolan, Gorman-Smith, \& Henry, 2003) or with compromised mental health and psychological adaptation (e.g., Argyle, 1999; Leventhal \& Brooks-Gunn, 2000). Our study adds to this line of research by demonstrating that the importance of regional characteristics for individual well-being that is established for earlier phases of life extends to the last years of life. This is important because it suggests that late-life well-being is influenced by resources and strains that are more distal to, and not fully captured by, individual-level measures typically included in studies of well-being correlates. Moreover, the large majority of studies thus far have been restricted to examining cross-sectional associations with levels of well-being. In contrast, our study extends these reports by focusing on developmental change and demonstrating that community and regional factors are as important for the course of late-life change as they are for static differences (see also D. Hart, Atkins, \& Matsuba, 2008; Odgers et al., 2009; Stafford, Gimeno, \& Marmot, 2008). More specifically, whether people show precipitous declines in well-being with impending death or are capable of maintaining well-being into the last phases of life appears to be considerably affected by where people live.

Using three-level growth models, we were able to quantify the relative contribution of county-level differences (as one instantiation of community characteristics) to late-life well-being and its progression toward the end of life. We note, however, that the explained variance depends on the regional unit utilized and may reveal larger or smaller effect sizes with different units. We nevertheless found it striking that regional differences, as defined by county, accounted for about $8 \%$ of the differences in both level and late-life change in well-being. Put differently, a sizable amount of disparities in the progression of well-being at the very end of life is not due to differences between persons but in reality reflects differences between the residential areas where people live. This finding is important in and of itself. We now have a rough quantification of the extent to which late-life individual development in a central component of quality of life (well-being) is shaped by the structure of opportunities and constraints in one's living environment (and presumably the policies that determine those structures). We note that the size of the overall regional-level effects appear to be somewhat larger than the $3 \%$ reported for variables of community health and well-being from other data sets and nations (Propper et al., 2005; Shields et al., 2009). It remains an open question whether these differences reflect national factors (e.g., Australia vs. Germany), procedural specifics of the studies (e.g., suburbs vs. counties), sampling features (e.g., total sample vs. decedents only), or particularities of the life phase considered (e.g., middle-aged workers vs. individuals close to death).

Having identified a set of distal factors that account for $8 \%$ of between-person disparities in well-being can be considered highly relevant for a number of reasons. First, proximal between-person correlates of well-being typically account for relatively minor 

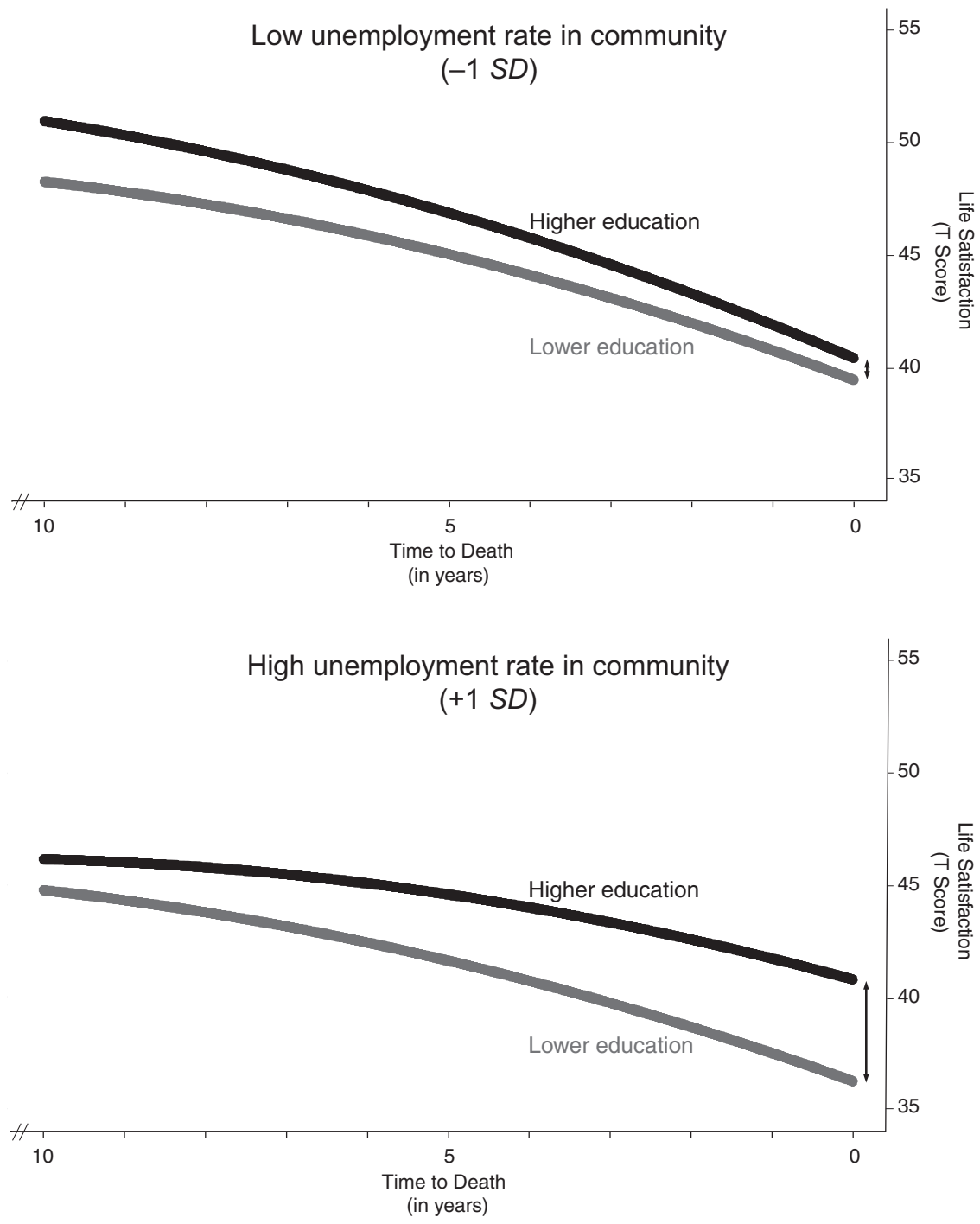

Figure 3. Illustration showing that community factors moderate the predictive effects of individual factors for differential end-of-life change in well-being. In counties with low unemployment rates (i.e., $-1 S D$ ), high- and low-educated Socio-Economic Panel Study participants show relatively minor differences in late-life level of satisfaction and change in life satisfaction (upper panel). In counties with high unemployment rates (i.e., $+1 S D$ ), in contrast, differences between education groups in both level and change in late-life well-being are exacerbated (lower panel). Education groups are based on mean split.

portions of the variance (for an overview, see Argyle, 1999). For example, correlations between well-being and education or income are often positive but rarely exceed $r=.20$, so that the amount of explained variance is around $4 \%$. Similarly sized associations have been reported for personality characteristics such as extraversion and neuroticism (for a meta-analysis, see Table 6 of DeNeve \& Cooper, 1998). In contrast, the size of our regional residency effect is rather comparable to that of health, which typically shows intercorrelations of about $r=.32$, thereby translating into $10 \%$ variance accounted for (for meta-analyses, see Okun, Stock, Haring, \& Witter, 1984; Table 14 of DeNeve \& Cooper, 1998). We also note that the size of the effect for change in well-being is probably even more striking because correlates of change in wellbeing are typically rare and often of minor size. Second, in the prior, referenced studies the between-person variance being accounted for represents a positively skewed distribution at the upper end of the response scale. As Biswas-Diener (2008) affectionately put it: "Most of the people are happy most of the time." In contrast, the between-person variance to be accounted for in our study is variability around an average trajectory of decline that is itself rather large by social science standards (1.0 SD and greater decline over a 10-year period). Third, our results suggest that prevention and intervention programs efficiently implemented and monitored at the community or county level can be expected to produce effects for a large number of people, relative to the number of people that might be affected by individual-level interventions. It is in this sense that an effect of approximately $8 \%$ in terms of both levels and changes in individuals' late-life well-being may have 
substantial implications and represent an important effect at the societal level. Another factor worth noting is that by virtue of our multilevel modeling procedure and the statistical controls for key individual-level correlates (age at death, gender, education, and household income), our study provides evidence that the effects of regional residency characteristics go beyond those provided by these individual characteristics (omitted variables not withstanding). This is noteworthy because one of the major debates in the field is whether neighborhood effects are compositional in nature (i.e., due entirely to the accumulation of characteristics of the individuals comprising the neighborhood) or persist net of individual characteristics (Wight, Cummings, Karlamangla, \& Aneshensel, 2009).

The evidence that regional differences exist in end-of-life wellbeing serves as a first step toward highlighting an important issue for research and policy. The next steps are to identify further which specific regional factors contribute to those disparities to better understand how macro-level characteristics permeate or "get under the skin" of individuals (Seeman, 2001). After reviewing the individual-level predictors, we discuss each of these points in turn.

\section{Individual and County Predictors of Differences in Late-Life Well-Being}

Our second objective was to explore the role of individual and county variables in accounting for the observed between-person differences in end-of-life well-being. Our results revealed predictive effects of individual factors. Consistent with the view that very old individuals are at the limits of their adaptive capacity (Baltes \& Smith, 2003) and, corroborating earlier results (Gerstorf, Ram, Röcke, et al., 2008), our findings suggest increasingly steep mortality-related declines with advancing age at death. It appears, prototypically, as if participants who died after age 70 years, and particularly after age 80 years, may not have the resources to ward off the detrimental effects of impending mortality and thus show steeper life-satisfaction decline with impending death relative to individuals who died earlier. We note, however, that, on average, participants who had died before age 70 showed somewhat attenuated, but still considerable mortality-related decline - an illustration of the pervasive nature of mortality-related processes. The evidence also suggests that the prevailing positive picture drawn by self-regulation theories needs qualification at the very end of life. The pervasive nature of impending death appears to render self-regulation capabilities increasingly fragile and inefficient. We also found well-being level and change effects for education. Such differences support a disadvantage perspective, in that persons with poor educational attainment may have larger health burdens and/or fewer resources to deal with late-life challenges (Diener et al., 1999; Pinquart \& Sörensen, 2001).

In line with earlier reports of well-being correlates at the end of life (Gerstorf, Ram, Estabrook, et al., 2008; Gerstorf, Ram, Röcke, et al., 2008), we found, with the exception of age and education, relatively few differences for the sociodemographic variables-an indication of the general need to explore the role of other variables both at the individual level and at other levels of analysis. At the individual level, future studies are needed to address the role of further etiologically relevant variables (e.g., relocation, health, or cognitive functioning) that we could not address in our secondary data analysis of a primarily economic study. For example, it appears conceivable that moving to a residential care facility along with the precursors that may necessitate such a move (e.g., physical limitations) and its consequences (e.g., limited contact with one's familiar social network) profoundly shape well-being change leading up to death. Similarly, systematic changes in well-being may be driven by the time course over which individuals experience an accumulation and increasing severity of chronic diseases and disability (see Ram, Gerstorf, Fauth, Zarit, \& Malmberg, 2010).

At the regional level, our results corroborate and extend earlier reports that neighborhood variables (of wealth and health care) have individual-level implications for health and well-being in adulthood and old age (e.g., Argyle, 1999; Krause, 1996; Shields et al., 2009; Silver et al., 2002). As a first contribution, our analyses extend the primarily cross-sectional reports from earlier phases of life and suggest that a positive manifold between regional socioeconomic advantage and individual function persists into the last years of life. As a second contribution, our results indicate that regional-level variables not only predict mean-level reports of well-being but also relate to developmental change trajectories, with county-level characteristics moderating the effects of individual-level characteristics. This is an important finding because we show that context matters in determining how well people adjust to the supposedly challenging late-life changes. Of note is that these county-level effects cannot be explained away by the key individual-level predictors included here. Instead, regional wealth and (to a lesser extent) health-care access appear to represent important variables that account for some of the individual differences we observe in end-of-life well-being. If we are to interpret the precipitous decline in well-being with approaching death as signifying major constraints on self-regulatory resources at the end of life (Baltes \& Smith, 2003), then our county-level effects indicate that the context in which people are living and dying imposes an additional set of limitations on, and opportunities for, this adaptive capacity.

As another contribution, we provide evidence for cross-level interaction effects that are consistent with Lawton's (1990) environmental docility notion, according to which contextual factors differentially affect "needy" population segments (for a discussion, see Subramanian et al., 2006; Wight et al., 2009). Our cross-level interaction effects suggest that associations between individuallevel factors and late-life well-being trajectories do not operate similarly across different contexts. Differences in the progression of well-being are significantly exacerbated in socioeconomically deprived areas, suggesting that, within a given county, wealthier individuals may know of, have access to, and utilize additional resources outside the community. In contrast, their less wealthy peers appear to be more strongly affected by a relative lack of local community resources. Such findings have profound societal implications, for example, by highlighting that it is particularly the most vulnerable segments of society that suffer from the most detrimental effects (e.g., strongest decline among the least advantaged sociodemographic strata in the least privileged counties). Of course, future studies are needed to corroborate these initial findings and to explore whether and how such cumulative disadvantages (see Dannefer, 2003; Marmot \& Wilkinson, 1999) can be alleviated by targeted intervention programs.

Our expectation was that individuals who spent the last years of their lives in communities with a dense system of high-quality 
health care would have better chances of maintaining well-being as compared with individuals living in communities with poor healthcare access. However, we found only very limited evidence that differences in well-being close to death are related to disparities in health-care access. One possibility is that our indicator variable (relative number of medical doctors per county) was a suboptimal proxy for the health service environment, a point we discuss further below. Another interpretation is that the story is simply more complex. Reports from the Alameda County study (Subramanian et al., 2006) and the Established Populations for Epidemiologic Studies of the Elderly (EPESE; Yen \& Kaplan, 1999) on the health implications of one's living area suggest a reversed pattern of differences. These studies found that individuals living in neighborhoods with higher density of service were characterized by worse health and higher all-cause mortality rates relative to individuals living in poor-service neighborhoods. The discrepant findings suggest that additional mechanisms are operating that overshadow, nullify, or reverse the relationship between health care and well-being. For example, medical personnel may selectively migrate into more needy areas, where help is most needed and where jobs exist. Clearly, more research is needed before conclusive inferences can be drawn regarding the provision of health-care services and its impact on end-of-life well-being.

\section{Limitations and Outlook}

Conceptually, it remains an open question what the actual mechanisms are that relate regional factors to between-person disparities in the progression of late-life well-being. It was beyond the scope and possibilities of our exploratory and primarily descriptive study to pinpoint possible mechanisms. Future endeavors targeting the etiological role of the service, the social, and the physical environment (or a combination of these) can inform a variety of broader theoretical accounts that all highlight the contextual integration of individual development, whether it is through the lens of environmental gerontology (Lawton, 1982; Wahl, 2001), through that of human ecology (Bronfenbrenner, 1979), or from a broader sociological and demographic perspective (e.g., social disorganization; Faris \& Dunham, 1939; Sampson et al., 1997). One promising route might involve examining the particular factors that serve to translate or mediate neighborhood effects at the individual level. Candidate "carrier variables" would include facets of social support, the duration of residency, the subjective perception of objective neighborhood environments, and stress-related mechanisms (e.g., impoverished counties represent stressful environments by constraining the pursuit of daily routines). It would also be instrumental to examine processes of residential selection and mobility more thoroughly. In our context, social drift may be possible in that individuals who are close to death may lose parts of their income and savings and thus be forced to move from wealthier to poorer neighborhoods.

Reasons for selecting the county as the unit of analysis in our study were related to data availability and comparability of units across time. Given its political jurisdiction in Germany, countylevel information was richer and available (at least for some indicators) since inception of the SOEP in the mid-1980s, whereas information for communities and boroughs was not available before the year 2000. In addition, widespread restructuring of communities and boroughs after German reunification creates substan- tial issues for data comparability at the community and borough level across the study period. Concerns are lessened by the fact that the structure of German municipal administrations in larger cities overlaps substantially (32\%) with both the county and community administration (i.e., a city is a county). However, we note several issues that concern how to best represent and measure a given context analytically.

A first possible concern relates to the level of geographic specificity considered. We selected the county as the unit of analysis in lieu of smaller units (e.g., housing blocks or census tracts) or larger units (e.g., clusters of counties or states or comparisons of what were formerly East and West Germany) given that this level of aggregation assured a reasonable balance among the number of observations within each unit and the substantive specificity of this unit. In our study, we had a median of six persons per county, which can be considered near the absolute lower end of what would be necessary to characterize a given county. Although the study makes use of random sampling procedures, we acknowledge that the specific people included in the study may not necessarily be representative of the county level. This is certainly a more general issue that warrants attention and further exploration in future research, especially in psychological studies. In a similar vein, the regional conditions within each county may at times be rather heterogeneous. It is possible that smaller units of analysis (e.g., census tracts) represent more homogeneous proxies for neighborhood effects and might thereby reveal even larger effects than those reported here. If this speculation were true, one may argue that within-county heterogeneity may have worked against us in establishing that county characteristics contribute to late-life change in well-being. Our county-level investigation could then be considered a rather conservative test of the importance of regional residency characteristics. Unfortunately, however, we do not have the data to test such speculation empirically. It would also be instrumental to examine whether and how late-life well-being differences between larger units of analysis, such as areas that were formerly East and West Germany, dissolve when incorporating characteristics at the county level.

Second, in contrast to the single, relatively crude county characteristics on which we have focused, many studies have been able to make use of aggregate measures composed of multiple community factors that tap into the pervasiveness of (dis)advantages (e.g., Silver et al., 2002; composite of nine neighborhood structural characteristics). In future studies, it might thus be instrumental to proxy, for example, the availability and density of health care through a comprehensive composite that spans highly qualified health professions (e.g., proportion of medical doctors, registered nurses) and other health-related services (e.g., pharmacies, hospital beds, ambulatory health centers). Use of such measures would allow for further investigation of whether individuals are able to compensate for a lack in service in one component of health care but unable to overcome the cumulative strains imposed by multiple deficits. Further, it may also be useful to complement the data on health-care availability and density with data that index aspects of health-care quality and accessibility. Other variables that hold promise include assessments of social cohesion, collective efficacy, and, more generally, an individual's perception of the environment (e.g., perceived social support among neighbors and sense of belonging to the community). Finally, the importance of changes in regional characteristics (e.g., declines in rates of un- 
employment or crime) or the relative comparisons on individuallevel outcomes should be considered (e.g., household income relative to neighborhood income: Deeg \& Thomese, 2005; Dittmann \& Goebel, in press).

In closing, evidence gathered from deceased participants in a nationally representative study suggests that disparities in wellbeing persist to the very end of life. Results revealed that individual difference variables, such as age, gender, education, and income, contribute to those disparities. As the major focus of our study, we have empirically demonstrated that structure and infrastructure characteristics of the regions in which people are living and dying also contribute to the reasons that some people are able to preserve their well-being into the last year(s) of life, whereas others show precipitous declines. The evidence even suggests that late-life disparities in well-being become exacerbated in structurally disadvantaged regions. Such results highlight the importance and utility of examining how contextual factors shape individual development. At the same time, more work is needed, both to substantiate our initial findings and to better understand the complex ways in which regional factors influence the progression of psychological health in the last years of a person's life. For example, it is not yet clear whether and how our results, obtained from deceased German respondents, generalize to other populations or geographic locations. We speculate that county-level effects on late-life well-being derived from data obtained in a European nation with comparatively small regional differences (Frick \& Goebel, 2008) and obligatory health insurance provide a rather conservative estimate for the resources that promote well-being or hazards that jeopardize well-being operating at the regional level in other, more diverse, nations such as the United States. It remains to be seen whether such a hypothesis can be corroborated with empirical data. Such insights can, in turn, inform social policies geared toward alleviating the societal and personal costs of latelife decline and help alleviate any imbalances between personal needs and environmental resources that arise at the end of life.

\section{References}

Aneshensel, C. S., Wight, R. G., Miller-Martinez, D., Botticello, A. L., Karlmangla, A. S., \& Seeman, T. E. (2007). Urban neighborhoods and depressive symptoms among older adults. Journal of Gerontology: Social Sciences, 62B, S52-S59.

Argyle, M. (1999). Causes and correlates of happiness. In D. Kahnemann, E. Diener, \& N. Schwarz (Eds.), Well-being: The foundations of hedonic psychology (pp. 353-373). New York: Sage.

Balfour, J. L., \& Kaplan, G. A. (2002). Neighborhood environment and loss of physical function in older adults: Evidence from the Alameda County Study. American Journal of Epidemiology, 155, 507-515. doi: 10.1093/aje/155.6.507

Baltes, P. B. (1987). Theoretical propositions of life-span developmental psychology: On the dynamics between growth and decline. Developmental Psychology, 23, 611-626. doi:10.1037/0012-1649.23.5.611

Baltes, P. B. (1997). On the incomplete architecture of human ontogeny: Selection, optimization, and compensation as foundation of developmental theory. American Psychologist, 52, 366-380. doi:10.1037/0003066X.52.4.366

Baltes, P. B., \& Smith, J. (2003). New frontiers in the future of aging: From successful aging of the young old to the dilemmas of the fourth age. Gerontology, 49, 123-135. doi:10.1159/000067946

Bandura, A. (1986). Social foundations of thought and action: A social cognitive theory. Englewood Cliffs, NJ: Prentice Hall.
Beard, J. R., Blaney, S., Cerda, M., Frye, V., Lovasi, G. S., Ompad, D., Rundle, A., \& Vlahov, D. (2009). Neighborhood characteristics and disability in older adults. Journal of Gerontology: Social Sciences, 64B, 252-257. doi:10.1093/geronb/gbn018

Berkman, L. F., Glass, T., Brisette, I., \& Seeman, T. E. (2000). From social integration to health: Durkheim in the new millennium. Social Science and Medicine, 51, 843-857. doi:10.1016/S0277-9536(00)00065-4

Biswas-Diener, R. (2008). Happiness interview with Ed Diener and Robert Biswas-Diener. Retrieved from http://www.happiness-project.com/ happiness_project/2008/09/happiness-int-1.html

Brandtstädter, J. (1999). Sources of resilience in the aging self: Toward integrating perspectives. In T. M. Hess \& F. Blanchard-Fields (Eds.), Social cognition and aging (pp. 123-141). San Diego, CA: Academic Press. doi:10.1016/B978-012345260-3/50007-0

Brickman, P., \& Campbell, D. T. (1971). Hedonic relativism and planning the good society. In M. Appley (Ed.), Adaptation-level theory (pp. 287-305). New York: Academic Press.

Brockmann, H., \& Klein, T. (2004). Love and death in Germany: The marital biography and its effect on mortality. Journal of Marriage and Family, 66, 567-581. doi:10.1111/j.0022-2445.2004.00038.x

Bronfenbrenner, U. (1979). The ecology of human development: Experiments by nature and design. Cambridge, MA: Harvard University Press.

Browning, C. R., \& Cagney, K. A. (2003). Moving beyond poverty: Neighborhood structure, social processes, and health. Journal of Health and Social Behavior, 44, 552-571. doi:10.2307/1519799

Burkhauser, R. V., Giles, P., Lillard, D. R., \& Schwarze, J. (2005). Until death do us part: An analysis of the economic well-being of widows in four countries. Journal of Gerontology: Social Sciences, 60, S238S246.

Cacioppo, J. T., Hughes, M. E., Waite, L. J., Hawkley, L. C., \& Thisted, R. A. (2006). Loneliness as a specific risk factor for depressive symptoms: Cross sectional and longitudinal analyses. Psychology and Aging, 21, 140-151. doi:10.1037/0882-7974.21.1.140

Carstensen, L. L. (2006). The influence of a sense of time on human development. Science, 312, 1913-1915. doi:10.1126/science.1127488

Clarke, P., \& George, L. K. (2005). The role of the built environment in the disablement process. American Journal of Public Health, 95, 19331939. doi:10.2105/AJPH.2004.054494

Cohen, S., \& Wills, T. A. (1985). Stress, social support, and the buffering hypothesis. Psychological Bulletin, 98, 310-357. doi:10.1037/00332909.98.2.310

Crimmins, E. M. (2001). Mortality and health in human life spans. Experimental Gerontology, 36, 885-897. doi:10.1016/S0531-5565(00)00248-5

Dannefer, D. (2003). Cumulative advantage/disadvantage and the life course: Cross-fertilizing age and social science theory. Journal of Gerontology: Psychological Sciences, 58B, S327-S337.

Deeg, D. J. H., \& Thomese, G. C. F. (2005). Discrepancies between personal income and neighborhood status: Effects on physical and mental health. European Journal of Ageing, 2, 98-108. doi:10.1007/ s10433-005-0027-4

DeNeve, K. M., \& Cooper, H. (1998). The happy personality: A metaanalysis of 137 personality traits and subjective well-being. Psychological Bulletin, 124, 197-229. doi:10.1037/0033-2909.124.2.197

Diehr, P., Koepsell, T., Cheadle, A., Psaty, B. M., Wagner, E., \& Curry, S. (1993). Do communities differ in health behaviors? Journal of Clinical Epidemiology, 46, 1141-1149. doi:10.1016/0895-4356(93)90113-F

Diener, E., Lucas, R. E., \& Scollon, C. N. (2006). Beyond the hedonic treadmill: Revising the adaptation theory of well-being. American Psychologist, 61, 305-314. doi:10.1037/0003-066X.61.4.305

Diener, E., Suh, E. M., Lucas, R. E., \& Smith, H. L. (1999). Subjective well-being: Three decades of progress. Psychological Bulletin, 125, 276-302. doi:10.1037/0033-2909.125.2.276

Dittmann, J., \& Goebel, J. (in press). Your house, your car, your education: The socioeconomic situation of the neighborhood and its impact on life 
satisfaction in Germany. Social Indicators Research. doi:10.1007/ s11205-009-9489-7

Elder, G. H. (1998). The life course and human development. In R. M. Lerner (Ed.), Handbook of child psychology: Vol. 1. Theoretical models of human development (5th ed., pp. 939-991). New York: Wiley.

Elder, G. H., Jr. (1974). Children of the great depression. Chicago: University of Chicago Press.

Ellen, I. G., Mijanovich, T., \& Dillman, K. N. (2001). Neighborhood effects on health: Exploring links and assessing the evidence. Journal of Urban Affairs, 23, 391-408. doi:10.1111/0735-2166.00096

Faris, R. E., \& Dunham, H. W. (1939). Mental disorders in urban areas: An ecological study of schizophrenia and other psychoses. Chicago: University of Chicago Press.

Frick, J. R., \& Goebel, J. (2008). Regional income stratification in unified Germany: A Gini decomposition approach. Regional Studies, 42, 555577. doi:10.1080/00343400701543181

Fujita, F., \& Diener, E. (2005). Life satisfaction set point: Stability and change. Journal of Personality and Social Psychology, 88, 158-164. doi:10.1037/0022-3514.88.1.158

Gerstorf, D., Ram, N., Estabrook, R., Schupp, J., Wagner, G. G., \& Lindenberger, U. (2008). Life satisfaction shows terminal decline in old age: Longitudinal evidence from the German Socio-Economic Panel Study (SOEP). Developmental Psychology, 44, 1148-1159. doi: 10.1037/0012-1649.44.4.1148

Gerstorf, D., Ram, N., Mayraz, G., Hidajat, M., Lindenberger, U., Wagner, G. G., \& Schupp, J. (2010). Late-life decline in well-being across adulthood in Germany, the United Kingdom, and the United States: Something is seriously wrong at the end of life. Psychology and Aging, 25, XXX-XXX.

Gerstorf, D., Ram, N., Röcke, C., Lindenberger, U., \& Smith, J. (2008). Decline in life satisfaction in old age: Longitudinal evidence for links to distance-to-death. Psychology and Aging, 23, 154-168. doi:10.1037/ 0882-7974.23.1.154

Hart, C., Ecob, R., \& Smith, G. D. (1997). People, places and coronary heart disease risk factors: A multilevel analysis of the Scottish Heart Health Study archive. Social Science Medicine, 45, 893-902. doi: 10.1016/S0277-9536(96)00431-5

Hart, D., Atkins, R., \& Matsuba, M. K. (2008). The association of neighborhood poverty with personality change in childhood. Journal of Personality and Social Psychology, 94, 1048-1061. doi:10.1037/00223514.94.6.1048

Heckhausen, J., \& Schulz, R. (1995). A life-span theory of control. Psychological Review, 102, 284-304. doi:10.1037/0033-295X.102.2.284

House, J. S., Landis, K. R., \& Umberson, D. (1988). Social relationships and health. Science, 241, 540-545. doi:10.1126/science.3399889

Jürges, H. (2009). Health insurance status and physician behavior in Germany. Schmollers Jahrbuch, 129, 297-307.

Kawachi, I., \& Berkman, L. F. (2003). Neighborhoods and health. New York: Oxford University Press. doi:10.1093/acprof:oso/9780195138382.001.0001

Kim, D., Subramanian, S. V., Gortmaker, S. L., \& Kawachi, I. (2006). US state- and county-level social capital in relation to obesity and physical inactivity: A multilevel, multivariable analysis. Social Science and Medicine, 63, 1045-1059. doi:10.1016/j.socscimed.2006.02.017

Kleemeier, R. W. (1962). Intellectual changes in the senium. Proceedings of the Social Statistics Section of the American Statistical Association, 1, 290-295.

Klein, T. (1996). Determinants of institutionalization in old age. In R. Eisen, \& F. Sloan (Eds.), Long-term care: Economic issues and policy solutions (pp. 103-113). Boston: Kluwer.

Krause, N. (1996). Neighborhood deterioration and self-rated health in later life. Psychology and Aging, 11, 342-352. doi:10.1037/08827974.11.2.342

Krause, N. (2003). Neighborhoods, health, and well-being in late life. In
H.-W. Wahl, R. Scheidt, \& P. Windley (Eds.), Annual review of gerontology and geriatrics (Vol. 23, pp. 223-249). Berlin, Germany: Springer.

Kroh, M., Pischner, R., Spieß, M., \& Wagner, G. G. (2008). On the treatment of non-original sample members in the German Household Panel Study (SOEP): Tracing and weighting. Methoden-DatenAnalysen, 2, 179-198.

Kroh, M., \& Spieß, M. (2006). Documentation of sample sizes and panel attrition in the Socio Economic Panel (SOEP) (1984 until 2005) (DIW Data Documentation 15). Berlin, Germany: DIW Berlin.

Kunzmann, U., Little, T. D., \& Smith, J. (2000). Is age-related stability of subjective well-being a paradox? Cross-sectional and longitudinal evidence from the Berlin Aging Study. Psychology and Aging, 15, 511526. doi:10.1037/0882-7974.15.3.511

Lachman, M. E. (2006). Perceived control over age-related declines: Adaptive beliefs and behaviors. Current Directions in Psychological Science, 15, 282-286. doi:10.1111/j.1467-8721.2006.00453.x

Lawton, M. P. (1982). Competence, environmental press, and the adaptation of older people. In M. P. Lawton, P. G. Windley, \& T. O. Byerts (Eds.), Aging and the environment (pp. 33-59). New York: Springer.

Lawton, M. P. (1990). Residential environment and self-directedness among older people. American Psychologist, 45, 638-640. doi:10.1037/ 0003-066X.45.5.638

Lerner, R. M. (1991). Changing organism-context relations as the basic process of development: A developmental contextual perspective. Developmental Psychology, 27, 27-32. doi:10.1037/0012-1649.27.1.27

Lerner, R. M., \& Kauffman, M. B. (1985). The concept of development in contextualism. Developmental Review, 5, 309-333. doi:10.1016/02732297(85) $90016-4$

Leventhal, T., \& Brooks-Gunn, J. (2000). The neighborhoods they live in: The effects of neighborhood residence on child and adolescent outcomes. Psychological Bulletin, 126, 309-337. doi:10.1037/00332909.126.2.309

Littell, R. C., Miliken, G. A., Stoup, W. W., \& Wolfinger, R. D. (1996) SAS system for mixed models. Cary, NC: SAS Institute.

Little, R. J. A., \& Rubin, D. B. (1987). Statistical analysis with missing data. New York: Wiley.

Lucas, R. E., Clark, A. E., Georgellis, Y., \& Diener, E. (2003). Reexamining adaptation and the set point model of happiness: Reactions to changes in marital status. Journal of Personality and Social Psychology, 84, 527-539. doi:10.1037/0022-3514.84.3.527

Magnusson, D. (Ed.). (1996). The lifespan development of individuals: Behavioral, neurobiological and psychosocial perspectives: A synthesis. Cambridge, England: Cambridge University Press.

Magnusson, D., \& Cairns, R. B. (1996). Developmental science: Toward a unified framework. In R. B. Cairns, G. H. Elder, \& E. J. Costello, (Eds.), Developmental science (pp. 7-30). New York: Cambridge University Press. doi:10.1017/CBO9780511571114.003

Marmot, M., \& Wilkinson, R. G. (1999). The social determinants of health. Oxford, United Kingdom: Oxford University Press.

Matteson, D. W., Burr, J. A., \& Marshall, J. R. (1998). Infant mortality: A multilevel analysis of individual and community risk factors. Social Science Medicine, 47, 1841-1854. doi:10.1016/S0277-9536(98)00229-9

Moen, P. (1996). Gender, age, and the life course. In R. H. Binstock \& L. K. George (Eds.), Handbook of aging and the social sciences (4th ed., pp. 171-187). San Diego, CA: Academic Press.

Mroczek, D. K., \& Spiro, A., III. (2005). Change in life satisfaction during adulthood: Findings from the Veterans Affairs Normative Aging Study. Journal of Personality and Social Psychology, 88, 189-202. doi 10.1037/0022-3514.88.1.189

Odgers, C. L., Moffitt, T. E., Tach, L. M., Sampson, R. J., Taylor, A., Matthews, C. L., \& Caspi, A. (2009). The protective effects of neighborhood collective efficacy on British children growing up in deprivation: A developmental analysis. Developmental Psychology, 45, 942 957. doi:10.1037/a0016162 
Okun, M. A., Stock, W. A., Haring, M. J., \& Witter, R. A. (1984). The social activity/subjective well-being relation: A quantitative synthesis. Research on Aging, 6, 45-65. doi:10.1177/0164027584006001003

Palgi, Y., Shrira, A., Ben-Ezra, M., Spalter, T., Shmotkin, D., \& Kavé, G. (2010). Delineating terminal change in subjective well-being and subjective health. Journal of Gerontology: Psychological Sciences, 65B, 61-64. doi:10.1093/geronb/gbp095

Pinquart, M., \& Sörensen, S. (2001). Gender differences in self-concept and psychological well-being in old age: A meta-analysis. Journal of Gerontology: Psychological Sciences, 56B, P195-P213.

Propper, C., Jones, K., Bolster, A., Burgess, S., Johnston, R., \& Sarker, R. (2005). Local neighbourhood and mental health: Evidence from the UK. Social Science and Medicine, 61, 2065-2083. doi:10.1016/j.socscimed .2005 .04 .013

Ram, N., Gerstorf, D., Fauth, B., Zarit, S. H., \& Malmberg, B. (2010). Aging, disablement, and dying: Three time metrics for charting late-life change. Research in Human Development, 7, 27-44.

Ram, N., \& Grimm, K. J. (2007). Using simple and complex growth models to articulate developmental change: Matching method to theory. International Journal of Behavioral Development, 31, 303-316. doi: 10.1177/0165025407077751

Raudenbush, S. W., \& Bryk, A. S. (2002). Hierarchical linear models: Applications and data analysis methods (2nd ed.). Thousand Oaks, CA: Sage.

Rehdanz, K., \& Maddison, D. (2009). The amenity value of climate to German households. Oxford Economic Papers, 61, 150-167. doi: 10.1093/oep/gpn028

Riegel, K. F., \& Riegel, R. M. (1972). Development, drop, and death. Developmental Psychology, 6, 306-319. doi:10.1037/h0032104

Riley, M. W. (1987). On the significance of age in sociology. American Sociological Review, 52, 1-14. doi:10.2307/2095388

Robert, S. A. (1999). Socioeconomic position and health: The independent contribution of community socioeconomic context. Annual Review of Sociology, 25, 489-516. doi:10.1146/annurev.soc.25.1.489

Ross, C. E., \& Mirowsky, J. (2001). Neighborhood disadvantage, disorder, and health. Journal of Health and Social Behavior, 42, 258-276. doi: $10.2307 / 3090214$

Sampson, R. J., Morenoff, J. D., \& Gannon-Rowley, T. (2002). Assessing "neighborhood effects": Social processes and new directions in research. Annual Review of Sociology, 28, 443-478. doi:10.1146/annurev .soc.28.110601.141114

Sampson, R. J., Raudenbush, S. W., \& Earls, F. (1997). Neighborhoods and violent crime: A multilevel study of collective efficacy. Science, 277, 918-924. doi:10.1126/science.277.5328.918

Schilling, O. (2006). Development of life satisfaction in old age: Another view on the paradox. Social Indicators Research, 75, 241-271. doi: 10.1007/s11205-004-5297-2

Schimmack, U., Schupp, J., \& Wagner, G. G. (2008). The influence of environment and personality on the affective and cognitive component of subjective well-being. Social Indicators Research, 89, 41-60. doi: 10.1007/s11205-007-9230-3

Seeman, T. (2001). How do others get under our skin? Social relationships and health. In C. D. Ryff \& B. H. Singer (Eds.), Emotion, social relationships, and health (pp. 189-210). New York: Oxford University Press.

Shields, M. A., Price, S. W., \& Wooden, M. (2009). Life satisfaction and the economic and social characteristics of neighborhoods. Journal of Population Economics, 22, 421-443. doi:10.1007/s00148-007-0146-7

Silver, E., Mulvey, E. P., \& Swanson, J. W. (2002). Neighborhood structural characteristics and mental disorder: Faris and Durham revisited. Social Science and Medicine, 55, 1457-1470. doi:10.1016/S02779536(01)00266-0

Singer, J. D., \& Willett, J. B. (2003). Applied longitudinal data analysis:
Modeling change and event occurrence. New York: Oxford University Press.

Smith, J., \& Baltes, M. M. (1998). The role of gender in very old age: Profiles of functioning and everyday life patterns. Psychology and Aging, 13, 676-695. doi:10.1037/0882-7974.13.4.676

Stafford, M., Gimeno, D., \& Marmot, M. G. (2008). Neighborhood characteristics and trajectories of health functioning: A multilevel prospective analyses. European Journal of Public Health, 18, 604-610. doi: 10.1093/eurpub/ckn091

Subramanian, S. V., Kubzansky, L., Berkman, L., Fay, M., \& Kawachi, I. (2006). Neighborhood effects on the self-rated health of elders: Uncovering the relative importance of structural and service-related neighborhood environments. Journal of Gerontology: Social Sciences, 61B, S153-S160.

Suzman, R. M., Willis, D. E., \& Manton, K. G. (Eds.). (1992). The oldest old. New York: Oxford University Press.

Tesch-Roemer, C., Motel-Klingebiel, A., \& Huxhold, O. (2009, November). Changing lives in changing contexts: Findings form the German Ageing Survey (DEAS). Paper presented at the 62nd annual meeting of the Gerontological Society of America, Atlanta, GA.

Thompson, E. E., \& Krause, N. (1998). Living alone and neighborhood characteristics as predictors of social support in late life. Journal of Gerontology: Social Sciences, 53B, S354-S364.

Tolan, P. H., Gorman-Smith, D., \& Henry, D. B. (2003). The developmental ecology of urban males' youth violence. Developmental Psychology, 39, 274-291. doi:10.1037/0012-1649.39.2.274

Turner, B. F., \& Troll, L. E. (1994). Women growing older: Psychological perspectives. Thousand Oakes, CA: Sage.

Verbrugge, L. M., \& Jette, A. M. (1994). The disablement process. Social Science and Medicine, 38, 1-14. doi:10.1016/0277-9536(94)90294-1

Wagner, G. G., Frick, J. R., \& Schupp, J. (2007). Enhancing the power of household panel studies: The case of the German Socio-Economic Panel Study (SOEP). Schmollers Jahrbuch, 127, 139-169.

Wahl, H.-W. (2001). Environmental influences on aging and behavior. In J. E. Birren \& K. W. Schaie (Eds.), Handbook of psychology of aging (5th ed., pp. 215-237). San Diego, CA: Academic Press.

Wahl, H.-W., \& Lang, F. R. (2004). Aging in context across the adult life course: Integrating physical and social environmental research perspectives. In H.-W. Wahl, R. Scheidt, \& P. Windley (Eds.), Annual Review of Gerontology and Geriatrics (Vol. 23, pp. 1-33). Berlin, Germany: Springer.

Wen, M., Hawkley, L. C., \& Cacioppo, J. T. (2006). Objective and perceived neighborhood environment, individual SES, and psychosocial factors, and self-rated health: An analysis of older adults in Cook County, Illinois. Social Science and Medicine, 63, 2575-2590. doi: 10.1016/j.socscimed.2006.06.025

Wight, R. G., Cummings, J. R., Karlamangla, A. S., \& Aneshensel, C. S (2009). Urban neighborhood context and change in depressive symptoms in late life. Journal of Gerontology: Social Sciences, 64B, 247251. doi:10.1093/geronb/gbn016

Wohlwill, J. F. (1970). The emerging discipline of environmental psychology. American Psychologist, 25, 303-312. doi:10.1037/h0029448

Yen, I. H., \& Kaplan, G. A. (1999). Neighborhood social environment and risk of death: Multilevel evidence from the Alameda County Study. American Journal of Epidemiology, 149, 898-907.

Yen, I. H., Michael, Y. L., \& Perdue, L. (2009). Neighborhood environments in studies of health of older adults: A systematic review. American Journal of Preventive Medicine, 37, 455-463. doi:10.1016/ j.amepre.2009.06.022

Received August 24, 2009

Revision received March 12, 2010

Accepted March 18, 2010 